\title{
Aspectos: O Problema na Matemática Escolar e o Dilema como Acontecimento
}

\author{
Aspects: The Problem in School Mathematics and the Dilemma as an \\ Event
}

\section{Carolina Tamayo ${ }^{\mathrm{a}}$; Jackeline Mendes ${ }^{\mathrm{b}}$}

a Faculdade de Educação, Universidad de Antioquia, Medellín, Colômbia - carolina.tamayo36@gmail.com b Faculdade de Educação, Universidade Estadual de Campinas, Campinas, Brasil - rodrigues@mpc.com.br

Palavras-chave:

Educação indígena.

Etnomatemática.

Resolução de problemas.

Matemática.
Resumo: Este texto, organizado através de uma cena ficcional, desenvolve-se a partir de seis Atos. A cena foi construída a partir de vozes espectrais, no sentido de Jacques Derrida, as quais são produzidas a partir de duas pesquisas doutorais ocorridas em temporalidades distintas. A proposta na construção da cena é tecer familiaridades entre efeitos sentido em torno do problema e do dilema, com base em uma abordagem não linear do tempo. Deste modo, procuramos percorrer diversos usos das palavras: problema e dilema. Com essas encenações, propomos desconstruir a noção de problema na Educação Matemática e reverberar usos e sentidos outros. Esse movimento propõe pensar os modos em que os dilemas são mobilizados nas práticas sociais e os seus possíveis efeitos no campo das práticas escolares, deslocando da pergunta o que é um problema? para as perguntas: Como, nas práticas sociais, se manifesta, na possibilidade do impossível, o aparecimento do acontecimento? Como dilemas acontecem? Quando resolvemos um dilema?.

\section{Keywords:}

Indigenous education. Ethnomathematics. Problem solving. Mathematics.

\begin{abstract}
This text is organized through a fictional scene, which has developed in six Acts. The scene was constructed from spectral voices, in sense of Jacques Derrida, which are produced from two doctoral researches, occurred in different temporalities. The proposal of scene construction is to weave familiarities between effects of meaning around problem and dilemma, based on a non-linear approach of time. In this way, we try to cover several uses of the words: problem and dilemma. With these scenarios, we propose to deconstruct the notion of problem in Mathematics Education and to reverberate other uses and senses. This movement proposes to think about the ways in which dilemmas are mobilized in social practices and their possible effects in the field of school practices. Moving from the question "what is a problem" to the questions: how is manifested the possibility impossible of event appearance in social practices? How do dilemmas happen? When do we solve a dilemma?"
\end{abstract}


*** A cena acontece na interação entre diversas vozes espectrais como professores indígenas e pesquisadores das áreas da educação e da filosofia em que se propõe deslocar da pergunta "o que é um problema" para as perguntas "como nas práticas sociais se manifesta, na possibilidade do impossível, o aparecimento do acontecimento? Como dilemas acontecem? Quando a gente resolve um dilema?"***

\section{Ato I}

[Todos chegam na sala e encontram no quadro a seguinte pergunta com algumas respostas. Todos se põem a ler silenciosamente os textos]

O que é um problema?

O que é um problema? Um problema é uma determinada questão ou um determinado assunto que requer uma solução. A nível social, trata-se de um assunto particular que, uma vez resolvido, se torna benéfico para a sociedade. Na acepção da religião cristã, um problema pode ser uma contradição interna entre dois dogmas (como é que um Deus omnibenevolente e todo poderoso permite que haja sofrimento? $)^{1}$.

O que é um problema? Conflito afetivo que impede ou afeta o equilíbrio psicológico do indivíduo. Questão não solvida e que é desejo de discussão, em qualquer domínio do conhecimento. Questão proposta para que se dê a solução. Proposta duvidosa que pode ter diversas soluções. (Conforme cita o Dicionário Aurélio, 2018)

O que é um problema? É a situação que constitui o ponto de partida de qualquer indagação, ou seja, a situação é indeterminada. Ela se torna problemática no próprio processo de sujeição à indagação. (DEWEY, 1938)

O que é um problema? Problema é qualquer situação que exija o pensar do indivíduo para solucioná-la. Qual quer situação que exija a maneira matemática de pensar e conhecimentos matemáticos para solucioná-la. (DANTE,1989, p. 9-10).

\section{Ato II}

$\mathbf{E S}^{2}$ - Então, vocês viram essas definições que estão no quadro? O que é um problema?

\section{[Silêncio]}

$\mathbf{E S}^{\mathbf{3}}$ - Queria conversar com vocês sobre a ideia de problema. Para a gente poder entender sobre problema. O que é um problema? Quando a gente tem um problema para resolver? Que formas diferentes podemos pensar a história de um problema? O que quer dizer a palavra problema? Vamos pensar um pouco, por exemplo, quando eu chego e falo com alguém e digo "Ailu eu estou com um problema ... rapaz!" O que você vai falar se eu te falar aí que eu estou com um problema ...

\footnotetext{
${ }^{1}$ Disponível em https://conceito.de/problema. Acessado em 24/09/2017

${ }^{2}$ Aqui a sigla $E S$ refere-se a espectro de uma educadora (in memoriam) em interação com professores indígenas do curso de formação para o magistério do Parque Indígena do Xingu.

${ }^{3}$ Segmento de fala extraído da interação gravada numa aula produzida para o desenvolvimento da pesquisa de Mendes (2001, p. 148). Vale notar, que nesta fala como outras referenciadas neste artigo, optou-se por manter as caraterísticas da variedade de português falado nesse contexto.
} 
$\mathbf{S K}^{4}$ - Ah eu posso dizer estou um problema aqui na perna, minha cabeça está doendo, pode ser assim né ...

ES - É verdade, às vezes tem uns problemas que deixam a gente triste e preocupado tentando achar uma forma de resolver para poder ficar melhor.

[ De repente várias vozes no fundo da sala aparecem nem presentes nem ausentes]

$\mathbf{O W}^{5}$ - Com licença... Quando eu penso num problema, é difícil falar o que é, mas na prática social, eu vejo que quando falta água na nossa região e temos dificuldade para alimentar os animais e cuidar do cultivo e cozinhar, é uma situação complicada que nos impede de viver bem, que implica procurar caminhos de solução.

CJ - Então, parece-nos que nas falas de vocês tem um deslocamento da pergunta o "que é um problema? Para pensarmos como nas práticas sociais se manifestam os imprevisíveis?. Isto faz com que os sujeitos parem para pensar em outras formas possíveis de agir que permitam atingir o proposito dessas práticas. Isto é, o aparecimento daquilo que não pode ser nem predito nem previsível. Acontecimentos imprevistos, daquilo que torna nosso ser-estar-fazer mais complexo. Em palavras de Jaques Derrida (JD):

O aparecimento do acontecimento, como o que chega, é o que verticalmente me cai no colo, sem que eu possa vê-lo vir: o acontecimento não pode me aparecer, antes de chegar, senão como impossível. Isso não quer dizer que isso não chega, que não o há; isso quer dizer que não posso dizê-lo em um modo teórico, que não posso nem mesmo o pré-dizer. Tudo isso, que concerne à invenção, à chegada, o acontecimento, pode deixar pensar que o dizer permanece ou deve permanecer desarmado, absolutamente desarmado, por essa impossibilidade mesma, desamparada diante da vinda sempre única, excepcional e imprevisível do outro, do acontecimento como outro: eu devo ficar absolutamente desarmado. [...] Dito de outro modo, a medida da possibilidade do acontecimento é dada por sua impossibilidade. (DERRIDA, 2012, p. 242 e 239. Itálico nossa).

CJ - Inverter e deslocar ${ }^{6}$ nosso olhar sobre aquilo que chamamos de problema provoca um afastamento da pergunta o que é?, para, questionarmos como acontecem os estranhamentos?. É como levarmos um susto que nos deixa momentaneamente paralisados, estupefatos... é como um saliêncio paralisante que provoca novas formas de agir quando estamos desenvolvendo uma prática social com um propósito específico, ou seja, isso acontece porque nos deparamos com os dilemas. Neste sentido Jean Lave afirma que,

O que motiva a atividade de resolução de problemas em atividades em situações do cotidiano aparece como dilemas que requerem solução. É necessário, ao manejar princípios contraditórios, chegar a uma solução em termos específicos e não necessariamente estáveis. Para um dilema não há solução factual e nem geral, em

\footnotetext{
${ }^{4}$ SK é uma voz espectral de um professor indígena Kuikuro extraída da pesquisa de Mendes (2001).

${ }^{5} \mathrm{OW}$ é uma voz espectral de um professor indígena Gunadule de Alto Caimán, Colômbia. Segmento de fala extraído da pesquisa de campo de Tamayo-Osorio (2017). Para efeitos desta encenação ficcional foram feitas algumas modificações na redação.

${ }^{6}$ Na perspectiva Derrida (2004) o processo de desconstrução opera na dobra entre, de um lado, a inversão das hierarquias naturalizadas que se manifestam no campo da filosofia como oposições, por exemplo, fala e escritura. De outro lado, é preciso deslocar suas estruturas, desmantelá-las e reinscrevê-las em outra forma de funcionamento.
} 
princípio, e nenhuma resposta correta. É um modo de confronto entre valores e alternativas viáveis, os quais não são corretos nem errados, e nenhum deles é inteiramente satisfatório. [...] Há dificuldade de se encontrar problemas na descrição da prática cotidiana, da mesma forma que no sentido convencional de um problema escolar. Na prática é difícil distinguir o problema de sua resolução, eles aparecem juntos. O problema na prática é um dilema com o qual o solucionador está emocionalmente engajado. (LAVE, 1993, p. 139 apud MENDES, 2001)

ES - Mas então.... Como nas práticas sociais se manifesta, na possibilidade do impossível, o aparecimento do acontecimento? Como dilemas acontecem? Quando a gente resolve um dilema?

$\mathbf{M M}^{7}$ - Se manifesta um problema, quando vivenciamos uma experiência fora do comum, quando estamos desenvolvendo uma prática social e devemos tomar decisões para que consigamos fazê-la corretamente. Por exemplo, quando vamos cultivar banana da terra e o terreno está muito perto do rio, isto limita o desenvolvimento da prática sociocultural Guna do cultivo, então, devemos avaliar, se vale, ou não, a pena, cultivar nessa zona. Mas, quando a gente tem pouca terra, aquilo se torna uma dificuldade, um problema, pois às vezes, não temos mais opções que cultivar e aguardar que ao chover não suba o rio e leve todo o cultivo. ES - Na sua fala, podemos ver que o aparecimento do dilema está relacionado com uma prática situada que envolve processos de escolha e decisão. Neste caso que você coloca, sobre a prática do cultivo da terra para os Guna, vocês decidem como agir diante do dilema, mas ao mesmo tempo tem de lidar com a incerteza. Vemos que com as suas respostas vocês estão nos deslocando de uma perspectiva de essência para tratarmos tal questão a partir da imanência, ou seja, não é o que é?, mas como acontece?.

CJ - Vamos ver se entendemos. Isto é, não queremos focalizar na resposta da pergunta pela sua essencialidade, mas pensar em perguntas que, na imanência, ocupam-se do acontecimento. Isto é, voltar nosso olhar para a experiência do como se, a qual opera na dobra provocada pela imanência da possibilidade do impossível que acontece ao ser-estar-fazer nas práticas sociais. Acontecimentos provocam quebras e dilemas aparecem diante da possibilidade do impossível nas práticas sociais, o aparecimento do dilema está naquilo que foge ao que planejamos, às nossas previsões, ao controle, e provoca efeitos e modos diferentes de produzirmos decisões e escolhas. Jacques Derrida (JD) se manifesta a respeito disso:

Um im-possível que não é só impossível, que não é só o contrário do possível, que é também a condição ou a ocasião do impossível. Um im-possível que é a experiência mesmo do possível. Para isto é preciso transformar o pensamento, ou a experiência, ou o dizer da experiência do possível ou do impossível. (DERRIDA, 2012, p. 244).

\footnotetext{
${ }^{7} M M$ é uma voz espectral de um professor indígena Gunadule de Alto Caimán. Segmento de fala extraído do trabalho de campo da pesquisa de Tamayo-Osorio (2017). Para efeitos desta encenação ficcional foram feitas algumas modificações na redação. Nesta fala tenta-se manter na tradução do espanhol para o português as caraterísticas da variedade do espanhol falado nesse contexto.
} 


\section{Ato III}

CJ - Inquieta-nos saber, como vocês lidam com o intempestivo, ou o imprevisível, em outras palavras, com aquilo que não se vê chegar ao estarem desenvolvendo uma prática sociocultural.

$\mathbf{J M}^{\mathbf{8}}$ - Muitos de nossos problemas os solucionamos na rede, pois na atualidade, continua a ser usada em todas as nossas atividades. Na rede, nossos problemas são resolvidos; nela, cantamos para os criadores e recebemos as crianças no nascimento. Avós, irmãs, caciques e mães continuam a iniciar o ensino, ali sentados com as crianças, cantando cantigas de ninar. Encostados na rede, nos balançando na rede, continuamos cantando e participando de diferentes rituais. Para nós, o movimento da rede é uma mistura entre passado, presente e futuro.

CJ - Nossa! Como assim na rede os seus problemas são resolvidos?

$\mathbf{J M}^{9}$ - São, sim. A rede tem um valor cultural para nós muito grande, como eu já disse, pois nela, no seu balançar, vivenciamos cada momento de nosso ser-estar sob a pele da Mãe Terra. Esta experiência de viver vem com os imprevistos e conflitos sociais e políticos que vivemos como indígenas e como coletivo que vive em comunidade. E então, cabe a nós, os caciques, nas reuniões na onmaggednega ${ }^{10}$ procurar soluções e castigos, para que consigamos conviver em nosso território. No fundo, cabe a nós, sermos justos ao resolver os imprevistos e conflitos na comunidade.

CJ - Isto que você nos diz, nos ajuda a entender como os acontecimentos, vistos a partir de sua imanência, nos permitem lidar com os efeitos dos dilemas. E, também, compreender, que cada dilema deve ser tratado forma diferente, não há soluções generalizáveis, estamos sempre agindo de um modo ou de outro numa prática.

KS $\mathbf{S}^{11}$ - Para nós indígenas no Brasil temos o problema da terra para pensar não só o cultivo mas garantir que elas sejam demarcadas. A terra indígena é um lugar demarcado, onde só os povos indígenas podem morar. "Se a terra não fosse demarcada ela tinha sido invadida há muito tempo. [...] Se não tivéssemos a terra indígena, teríamos muitas dificuldades de conseguir as coisas da natureza. A nossa terra indígena é importante para nosso povo viver. Nós temos direito de lutar e brigar para podermos fazer o que temos direito na terra". (Kaomi Kisedjê, Geografia indígena, 1988, p. 44)

\footnotetext{
${ }^{8} J M$ é uma voz espectral de um cacique Gunadule de Alto Caimán. O segmento de fala extraído de TamayoOsorio (2017, p. 21).

${ }^{9}$ Esta fala de $J M$ foi extraída do trabalho de campo produzido para a pesquisa de Tamayo-Osorio (2017).

10 "Onmaggednega - Casa del Congreso - é um dos espaços de formação do povo Gunadule. Os nele - guias espirituais - e os saglamala - caciques - Guna cantam diferentes histórias e dão conselhos sobre como se deve comportar individualmente na comunidade; "Os cantos e as narrativas constituem, sob nossa perspectiva, jogos alegóricos ou metafóricos de linguagem”. (TAMAYO-OSORIO, 2017, p. 12).

${ }^{11} K S$ nos remete ao espectro de Kaomi Kisedjê professor indígena. Alguns segmentos desta fala espectral foram extraídos do livro de autoria dos professores indígenas do Xingu intitulado Geografia indígena (1988, p. 44).
} 


\title{
Ato IV
}

$\mathbf{T K}^{\mathbf{1 2}}$ - Gente, mas tem o problema na escola também. Acho que um problema de contagem tem de falar sobre coisas do nosso dia a dia, as contagens que fazemos quando pescamos, caçamos, plantamos...

ES - Verdade! Pode ser um outro tipo de problema. A gente estava falando o tempo todo sobre essa ideia do dilema, mas quando a gente pensa na escola, a gente fala em problema, né! Se você fosse escrever um problema de contagem para seus alunos como você faria?

TK - Ah acho que eu diria assim: "Olha meus alunos, ontem eu fui pescar com meu irmão. Eu peguei três piraras, ele pegou cinco pacus total deu oito peixes. Chegamos na casa aí nós dividimos peixes para pessoal, demos dois para nosso vizinho" (MENDES, 2001, P. 135).

MK - Posso falar um outro problema?

ES - Sim fale.

MK - "Um dia meu cunhado foi pescar ele pegou 4 peixe 3 macaco e 2 quati. Aí, ele voltou para casa dele chegou na casa dele, e aí, ele assou peixe macaco quati para comer com beiju”. (MENDES, 2001, p. 134).

CJ - Interessante! As formas como vocês estão colocando os problemas da escola são muito parecidas com a forma como o Paiê Kaiabi escreveu um problema de matemática quando ele tinha aula com a Mariana. Ela que dava aula na escola da Funai lá pelos anos de 80 no Posto Indígena Diauarum, vejam como ele escreveu o problema dele:

\begin{abstract}
[PK ${ }^{13}$ - ] No dia 15 de maio, eu desci com Canísio para ele comprar 80 litros de gasolina. Ele aproveitou para levar 108 cachos de banana para vender para o pessoal do Bang Bang. Ele vendeu 500,00 cada um. Ele conseguiu vender só 50 cachos de banana. Saiu por $25.000,00$. O resto ele fez por 200,00 cada um. Só conseguiu vender 30 cachos de banana. Ele recebeu mais de 6.000,00. Total de dinheiro deu 31.000,00. O resto da banana ele deu para caraíba. (Paiê Kaiabi, RCNEI, 1998, p. 185).
\end{abstract}

CJ - A forma como Paiê Kaiabi retrata como o dilema se desenrola na prática, é estranha para nós professores de matemática, né! Pois apesar dele ter pensado essa situação numa aula de matemática na escola, não aparece pergunta no final como geralmente acontece nos problemas escolares.

$\mathbf{O W}^{\mathbf{1 4}}$ - Eu gostaria de falar a respeito. Quando eu penso na palavra problema, me vem na cabeça o que tentamos fazer na escola ou o que trazem os livros para efeitos de ensino, por exemplo de matemática.

CJ - Fale mais sobre isso, por gentileza.

\footnotetext{
${ }^{12} T K$ é uma voz espectral da escrita de um professor indígena Kaiwawete para a produção de um livro para as escolas indígenas do Parque Xingu, extraído da pesquisa de Mendes (2001).

${ }^{13}$ PK é o espectro de Paiê Kaiabi indígena da etnia Kaiwawete, na década de 80, aluno de Mariana K. Ferreira na escola da Funai, no Parque Indígena no Xingu.

${ }^{14}$ Segmento de fala extraído da pesquisa de campo de Tamayo-Osorio (2017).
} 
$\mathbf{O W}^{\mathbf{1 5}}$ - Pois é! Nas guias escolares organizadas por disciplinas, que o Ministério de Educação da Colômbia entrega para nossas escolas, aparecem textos escritos que são chamados de problemas, que devem ser resolvidos pelos alunos empregando conhecimentos da matemática ocidental. Olha aqui um exemplo:

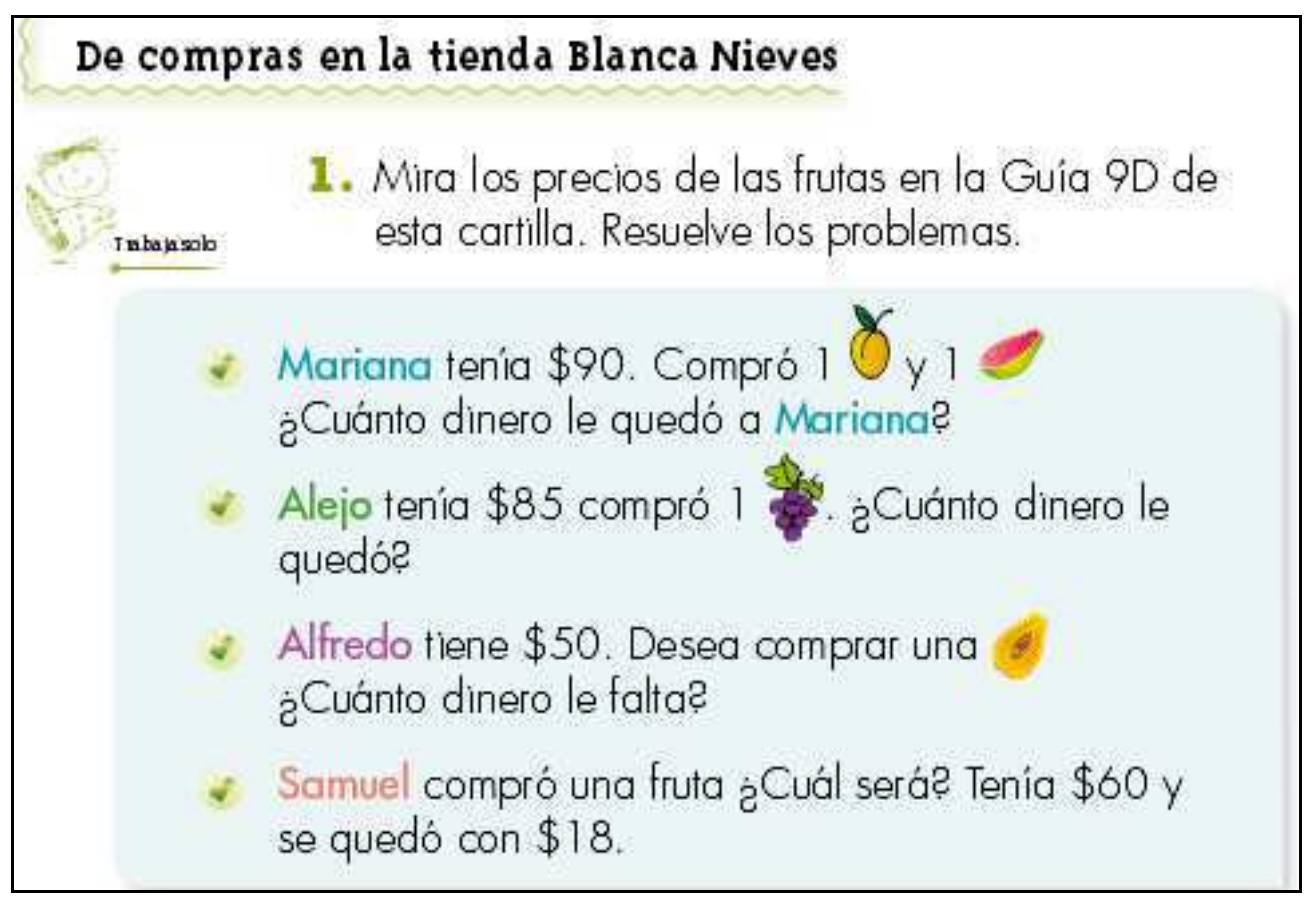

Figura 1: Exemplo de problema da cartilha da primeira série.

Fonte: MEN (2010).

$\mathbf{O} \mathbf{W}^{\mathbf{1 6}}$ - Isso. A questão é que essas situações não têm nada a ver com nossa comunidade, nem com as práticas que a gente desenvolve no dia a dia. As crianças e jovens, às vezes, não entendem os contextos dessas situações, não porque eles tenham menos capacidades, como disseram durante muito tempo as análises das avaliações externas, mas, porque essas experiências colocadas por escrito nada dizem para eles.

CJ - Isso que você está dizendo e o exemplo que você mostrou, apresenta uma certa artificialidade ao tratar de transferir a situação de uma prática social para a prática escolar, na qual, com o propósito de ensinar um conteúdo, e não de problematizar os dilemas como eles acontecem nas práticas. Se os focos da escola fossem às práticas sociais, tal e como elas acontecem, os dilemas não seriam tratados de forma artificial. Pensar num ensino a partir das práticas - e não do conteúdo - promoveria possibilidades outras de educação (matemática), organizadas de formas não disciplinares.

ES - A fala do professor Gunadule é interessante, pois, no seu exemplo, outro uso da palavra problema se manifesta. Aparece como aquilo que chega na sua comunidade como efeito da colonialidade $^{17}$ exercida mediante os efeitos dos processos de escolarização moderna. Tais guias escolares não estão nem em sintonia com a visão de educação de sua comunidade Guna

\footnotetext{
15 Ibid.

${ }^{16}$ Ibid.

${ }^{17}$ No sentido de Mignolo (2008).
} 
e nem em conformidade com o que aqui chamamos do aparecimento do acontecimento em sala de aula, isto é, o aparecimento do dilema. Eu gostaria de apresentar um exemplo sobre uma concepção de problema muito presente em vários manuais didáticos para ensino de matemática:

\begin{abstract}
La importancia que se da a la resolución de problemas en los currículos actuales es el resultado de un punto de vista sobre las matemáticas que considera que su esencia es precisamente la resolución de problemas. Muchos autores han ayudado a desarrollar este punto de vista como, por ejemplo, Lakatos. Entre estos autores se destaca Polya [...] La resolución de problemas es una parte integral de cualquier aprendizaje matemático, por lo que consideramos que no debería ser considerado como una parte aislada del currículo matemático. En consecuencia, la resolución de problemas debe estar articulada dentro del proceso de estudio de los distintos bloques de contenido matemático. Los contextos de los problemas pueden referirse tanto a las experiencias familiares de los estudiantes, así, como aplicaciones a otras áreas. Desde este punto de vista, los problemas aparecen primero para la construcción de los objetos matemáticos y después para su aplicación a diferentes contextos. (GODINO, 2002, p. 22 e 67).
\end{abstract}

ES - É interessante perceber nesta concepção que a resolução de problemas está sempre articulada com blocos de conteúdos matemáticos e, como ele afirma, é necessário primeiro a construção de objetos matemáticos para depois pensar em aplicações nas práticas. É como se a escola desse a chave de resolução para os dilemas que acontecem nas práticas. Isto é, as práticas estariam a serviço da matemática. Poderíamos pensar em fazer um movimento em outro sentido, partir dos dilemas que emergem nas próprias práticas para lidarmos com eles nas práticas escolares. Este último ponto requer mais estudo e, com o tempo que temos hoje, não damos conta dessa discussão.

\title{
Ato $\mathbf{V}$
}

ES - Vamos voltar a falar sobre os problemas que vocês escreveram para os livros de matemática.

[silêncio]

KJ - Quando a gente escreveu alguns problemas para fazer um livro de matemática em língua indígena, ficou desse jeito, vou falar em minha língua como ficou: "Nanuara ore orao pinaetyka, a'eramil futat ore pira manurugi 'nga irupawê je nanemt intpawê ipira mwa. Pemojotyka ipytuna isaka - Outro dia nós fomos pescar aí nós pegamos peixes. Eu peguei 4 peixes ele pegou 4 peixes, depois nós juntamos tudo- " (MENDES, 2001, p. 134).

YY - Mas o problema pode ser quando eu vou na cidade comprar roupas, o meu problema foi assim: "Eu comprei 2 shorts e para cada short paguei 15 reais, no total deu 30 reais, e depois comprei mais camisetas, para cada camiseta paguei 5 reais, no total deu 15 reais, depois comprei 2 calças, cada calça custa 25 reais, no total o que eu paguei com 100 reais e sobrou 5 na minha mão" (MENDES, 2001, p. 134). 
ES - Esses problemas mostram como aconteceu a situação na prática, vocês escreveram histórias com situações de quantificação, fazendo isso a partir de sua prática cotidiana. Mesmo querendo escrever um problema escolar encontramos rastros do dilema. Pois, pensando na linguagem, para resolver uma situação de quantificação, na prática nós não paramos, necessariamente, para fazer perguntas como na prática escolar. Vai acontecendo uma série de procedimentos, usamos as mãos, o pensamento, as palavras, o corpo, olhamos a formas e as cores para fazer escolhas, tudo isso para resolver um dilema. Retomando o que a Jean Lave já disse, na prática, é difícil separar o problema de sua solução.

CJ - A Jean Lave não faz referência de como a linguagem operaria no processo de resolução de dilemas na prática. É interessante perceber que as formas como vocês estão escrevendo esses problemas tentam se aproximar dos dilemas que se manifestam nas práticas do dia a dia, a partir da narrativa do acontecimento. No entanto, nós entendemos a linguagem como constitutiva da prática, a partir de todos os elementos de produção de sentido que fazem parte dessas situações: visual, gestual, diferentes formas de escritura, etc. Aparece uma diferença entre os dilemas que acontecem em práticas situadas e os problemas da prática escolar. Temos que pensar como os dilemas acontecem em cada contexto específico, e nos efeitos que podem ser provocados ao deslocá-los para campo da atividade escolar.

$\mathbf{M}^{\mathbf{1 8}}$ - É! Quando a gente pensou em fazer o livro pensamos em fazer histórias... histórias de adição, subtração ...

ES - "Essas histórias mostraram que tem um outro jeito que você pode contar uma história de um problema e já dar a resposta também, é uma outra forma de pensar sobre a solução de problemas? Vocês entenderam o que eu estou falando?” (MENDES, 2001, p. 148).

[silêncio]

Entendeu Ailu?

PK - Entendi mais ou menos.

ES - Mais ou menos

[Risos]

ES - Está no coração, mas ainda não tá na cabeça essa história ...Tá.

CJ - É interessante ver o silêncio que apareceu depois da pergunta. O silêncio indígena pode ser entendido como uma forma de mostrar que se ficou pensando sobre que foi falado. E, também, o silêncio pode ser uma resposta. E nós, não indígenas, temos de aprender com esse tempo de silêncio indígena, esquecemos que ele também faz parte da interação e tem sentido, a gente é que não tem paciência e fica jogando uma pergunta atrás da outra quando ficamos diante do silêncio ....

${ }^{18} M$ é uma voz espectral de um professor indígena Kaiwawete extraído da pesquisa de Mendes (2001). 
[Silêncio]

ES - Vamos ver os problemas que vocês fizeram para compor o livro de matemática em língua indígena. Aqui uma amostra que eu selecionei dos livros:

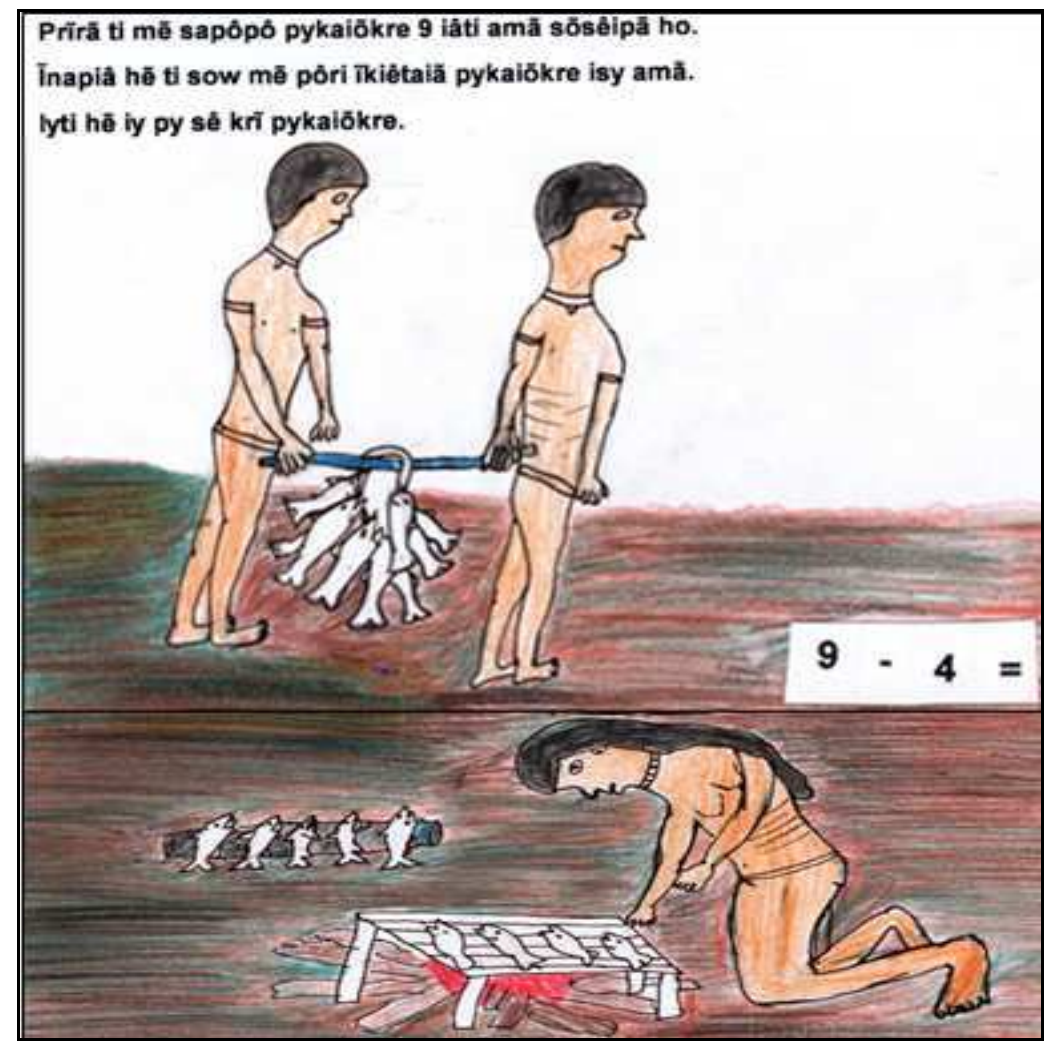

Figura 2: Problema em lingua indígena Panará

Fonte: livro de alfabetização matemática em lingua indígena Panará (1999).

Nanuara kujămera 'ngã oo kope ai'i kisa.

A'eramū 'ngä tamakari rerawaw pawe pawe.

Ajeia e̊ irũpawëa mamăo reruate, ęễ irũ ẽ irũpawe reruajaw.

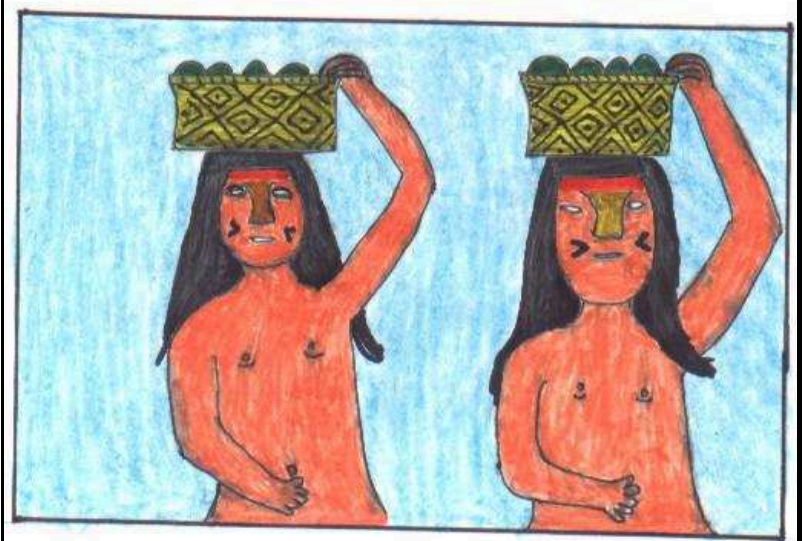

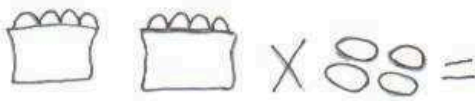

Nanuaraje oo tekow teataw 'ikuĩ:

A'era mytūa upa wopi'a'arimũ rai'i.

A'eraũ owewewjui.

A'eraũ jetewaw tejewpia jupe; tewaw tewawma jupe a'eraũ irŭpãwẽa upiaa rai'i.

Teatau'i nũ amũ owewew nũ; tewaw waaka nũ, a'eraũ irupawe wejemi nũ.

A'eraũ tat je imua jui. Ogipe je imojo'oka 'kunumi'nga nupe.
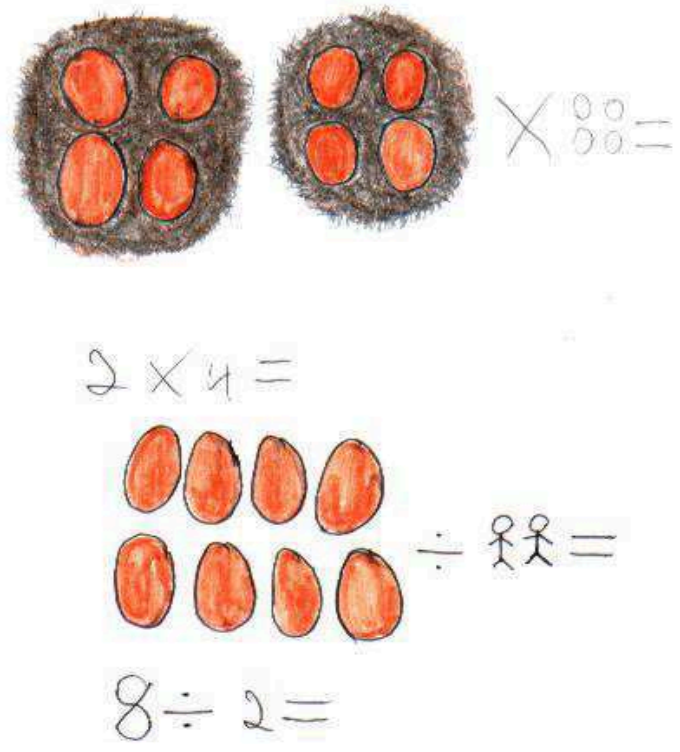

$8 \div 2=$

Figura 3: Problema lingua indígena Kawaiwete.

Fonte: livro de alfabetização matemática em lingua indígena Kawaiwete (1999). 
MM - Eu que não sei falar suas línguas consigo entender o que está em jogo com essas imagens por vocês desenhadas. Também, eu queria mostrar o modo em que temos lidado com isso nos poucos livros para ensino, produzidos pelo nosso povo:

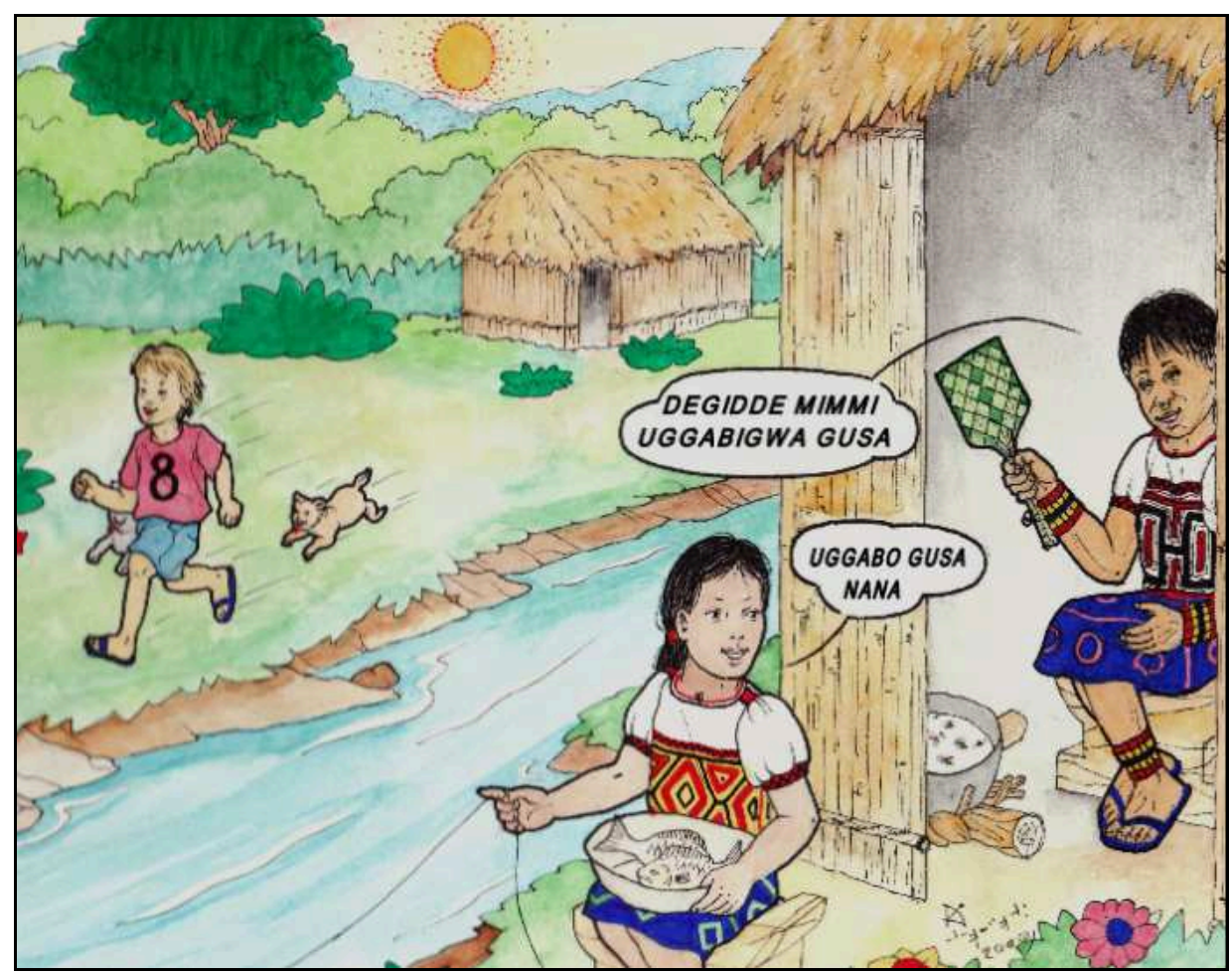

Figura 4: Problema em lingua Guna

Fonte: Ayarza (2010, p.1).

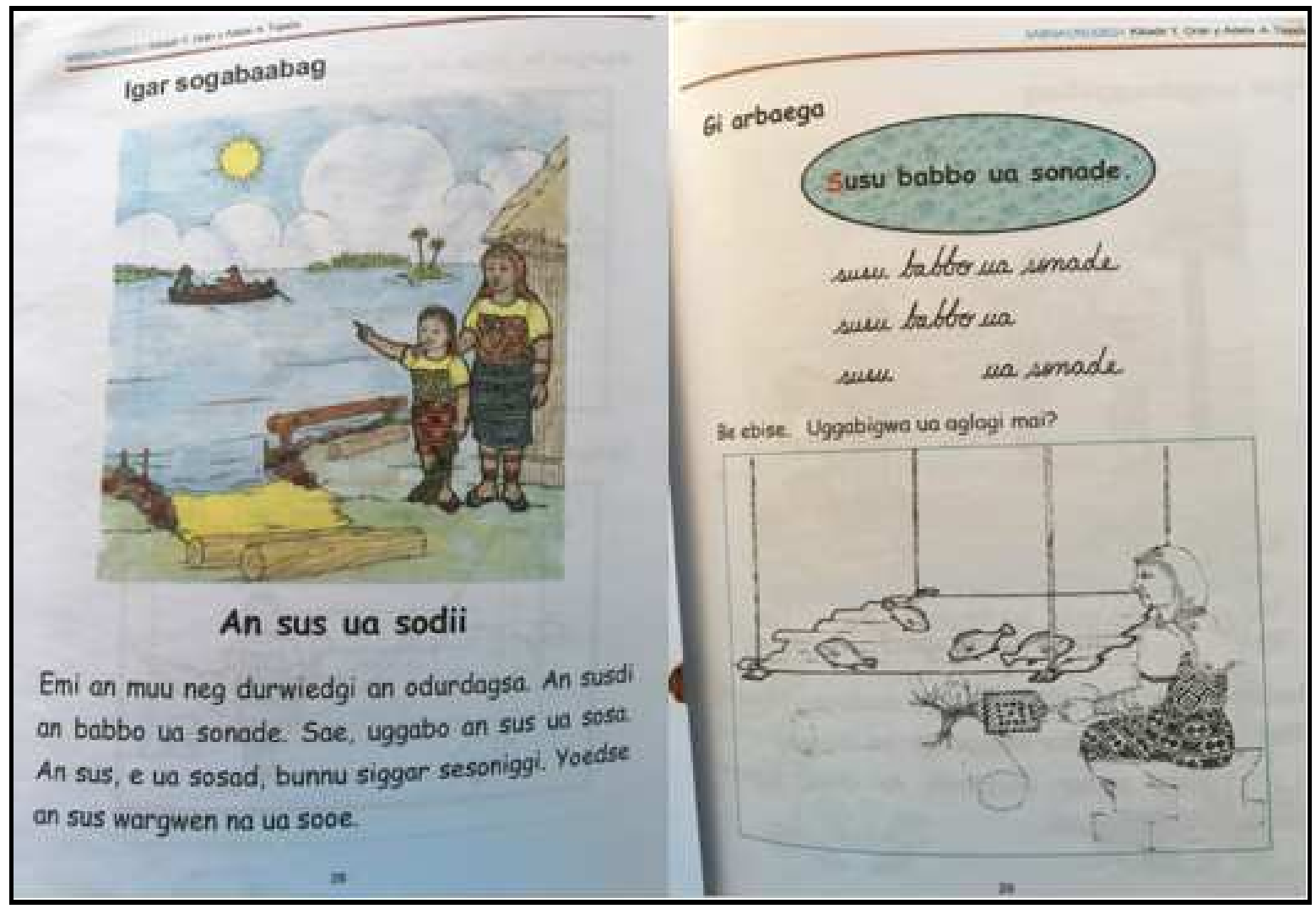

Figura 5: Problema em lingua Guna

Fonte: Kikadir et all. (2011, p.28-29). 
CJ - A ideia da narração aparece também nesses problemas, e as imagens parecem não ser meramente ilustrativas, elas têm um papel nessa narração. $O$ desenho acaba tendo um papel de escritura, funcionando como uma forma de registro da narrativa também. Esses problemas feitos por vocês se diferenciam dos problemas da prática escolar, em que o uso de desenhos e da escrita numérica estão presentes para auxiliar o processo de resolução do problema. Entretanto, a colocação da pergunta faz uma divisão estanque entre o texto verbal e o texto aritmético, e o desenho, por sua vez, serve apenas de apoio visual.

\section{Ato VI}

ES - E, então? Que problema? Que dilema? Acontecimentos, imprevistos e experiências possíveis, isto é, usos possíveis das palavras.

CJ - O problema se distancia do dilema. O primeiro, opera no campo da prescrição, isto é, a linguagem é entendida dentro campo da representação ${ }^{19}$, ou seja, como mediadora. O dilema opera no campo da imanência e nos coloca diante da linguagem vista como um conjunto de encenações de dizeres e fazeres. Assim, não entendemos o acontecimento do dilema a partir da dicotomia 'pensamento e corpo' ou 'natureza e cultura'. Propomos entender o dilema como um conjunto de encenações da linguagem não apenas restrita aos processos verbais, nos quais, as imagens podem ser entendidas como escrituras, como nos problemas que vocês nos mostraram.

ES - Deixa ver se eu entendi o que vocês estão querendo dizer. Os dilemas são parte das próprias práticas socioculturais e estão inseridos em jogos de linguagens ${ }^{20}$ específicos. O que a gente está fazendo aqui, é falar sobre diferentes jogos, de um lado, os jogos de linguagem da matemática escolar em que aparecem problemas, e, de um outro lado, jogos de linguagem não escolarizados nos quais aparecem dilemas. Eles têm algumas semelhanças entre si, mas também, têm diferenças, por quê? Porque as pessoas que participam desses diferentes tipos de jogos, em cada um deles, têm um jeito diferente de agir.

CJ - Essa sua fala é muito interessante, pois nos permite entender o dilema para além do que a Jean Lave propôs. O dilema se desdobra ao entendê-lo a partir do campo do acontecimento, enquanto sua possibilidade do impossível de aparecimento na própria vida, isto é, uma ampliação do sentido que se realiza como forma de experiência, entendida como o

\footnotetext{
${ }^{19}$ Vilela e Mendes (2011, p. 8) esclarecem os dois modos de conceber a linguagem que não são conciliáveis, isto é, "ou ela seria entendida como representação ou como constitutiva da realidade. Quando entendida como representação, seja de ideias, seja daquilo que se procura discutir como sendo realidade, ela é colocada como descritiva do mundo, dos conceitos e dos objetos. [...]. Outra possibilidade é a linguagem ser vista em termos de atividade, como constitutiva das coisas, e não como meramente "descritiva" delas".

${ }^{20}$ No sentido de Wittgenstein (1999).
} 
que nos atravessa $^{21}$ diante do incômodo que provoca instabilidade e demanda uma reinvenção do jogo.

ES - Gente, como vamos pensar o dilema na aula de matemáticaS ${ }^{22}$ ?

CJ - Trabalhar com dilemas não é fácil, pois já estamos acostumados a trabalhar com problemas na escola. Os exemplos que trouxemos dos livros mostram isso. A gente tenta contar a história com todas as coisas que podem acontecer na situação, mas a gente não dá conta. De um lado, ao escrever sobre as práticas sociais, ou fazer os desenhos, há um deslocamento, pois passamos a praticar um outro jogo de linguagem, ou seja, o jogo de linguagem da escrita alfabética ou do desenho. De um outro lado, por que a prática escolar não se modifica, ela espera que essas outras práticas entrem na forma como ela está organizada, será que é possível pensar nos dilemas na escola?

OW - Não sei, essa sua pergunta requer de mais aprofundamento. Talvez, para isso acontecer, precisaria uma escola diferente.

ES - Como assim diferente? Como vocês os Gunadule entendem essa questão da escola?

$\mathbf{O W}^{\mathbf{2 3}}$ - Sim, diferente. Tinha que pensar num ensino que não focalize o conteúdo nas práticas, mas que procure entender como as práticas sociais funcionam e como nelas são mobilizados saberfazeres. Sobre a escola, nós Gunadule temos uma expressão 'fazer escola' porque ela está fora de nossa vida. Assim, 'fazer escola' é problemático, uma vez que este espaço continua refletindo o poder colonial; entretanto, como instrumento político, a escola é necessária. Porque para nós educação acontece pela Onmaggednega que se expande para toda a vida da comunidade. Nessa educação aprendemos nas práticas. E os dilemas só acontecem dentro das práticas, por isso, eu acho que se a escola quer trabalhar com dilema é necessário que ela volte seu olhar para as práticas e não para o conteúdo.

[Silêncio]

CJ - Talvez dilemas aconteçam na sala de aula, será que sabemos como lidar com eles?

Água namora com a pedra

a pedra sempre feliz vai ficar

21 "Começarei com a palavra experiência. Poderíamos dizer, de início, que a experiência é, em espanhol, "o que
nos pass". Em português se diria que a experiência é "o que nos acontece"; em francês a experiência seria "ce
que nous arrive"; em italiano, "quello che nos succede" ou "quello che nos accade"; em inglês, "that what is
happening to us"; em alemão, "was mir passiert". A experiência é o que nos passa, o que nos acontece, o que
nos toca. Não o que se passa, não o que acontece, ou o que toca. A cada dia se passam muitas coisas, porém, ao
mesmo tempo, quase nada nos acontece". (LAROSSA, 2002, p. 19, itálico nosso).
${ }^{22}$ Esta transgressão na escrita foi cunhada no projeto "matemáticaS" desenvolvido pelo Grupo de Pesquisa
PHALA da FE-UNICAMP em parceria com LABJOR da mesma instituição e as produtoras Ana Paula Zaguetto
Alves e Patrícia Santos, do qual participamos e cuja produção final pode ser acessada no seguinte link:
bit.ly/projetomatematicas. A escolha pela letra "S" maiúscula no final da palavra faz um movimento
descontrutivo que opera na amplificação da significação, inspirados em Jacques Derrida. O "S" também tensiona
o desejo de manter um sistema explicativo universal e totalizante, vinculado à palavra Matemática com "M"
maiúsculo.
${ }^{23}$ Fala extraída do trabalho de campo de Tamayo-Osorio (2017). Foram feitas algumas modificações para efeitos
da encenação em jogo. 


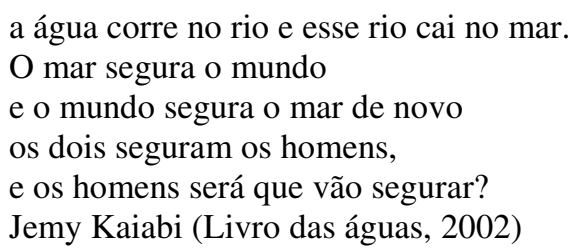

Referências:

AYARZA, V. ANMAR EBISE: Cartilla de Matemática Kuna. 2010. Disponível em http://www.etnomatematica.org/publica/libros/pub-cartillamatguna.pdf

DANTE, L. R. Didática da resolução de problemas de Matemática: $1^{a}$ a $5^{a}$ séries. São Paulo: Ática, 1989.

DERRIDA, J. Gramatologia. São Paulo: Ed. Perspectiva, 2004.

DERRIDA, J. Decir el acontecimento, es possible?: seminário de Montreal, para Jacques Derrida. Traducción de Julián Santos Guerrero. Madrid: Arena Libros, 2006.

DERRIDA, J. Uma certa possibilidade impossível de dizer o acontecimento/Une certaine possibilité impossible de dire l'événement. Trad. EYBEN, P. Revista Cerrados, 2012. Disponível em: http://periodicos.unb.br/index.php/cerrados/article/view/8242/6240

DEWEY, J. Logic The Theory Of Inquiry. Collection opensource. 1938.

GODINO, J. Didáctica de las matemáticas para maestros. 2002. Disponível em: https://www.ugr.es/ jgodino/edumat-maestros/manual/9_didactica_maestros.pdf

KIKADIR, Y.; TEJADA, A. Sabga Onoded. Texto aprovado pelo MEDUCA, Panamá. 2011.

LAVE, J. Cognition in Practice. Cambridge: Cambridge University Press. 1993.

LAROSSA. J. Notas sobre a experiência e o saber de Experiência. Revista Brasileira de Educação, n. 19, 2002.

MIGNOLO, W. D. A opção de-colonial: desprendimento e abertura. Um manifesto e um caso. Tabula Rasa, n .8, p. 243-282, 2008. Disponível em: http://www.scielo.org.co/scielo.php?pid=S1794$\underline{24892008000100013 \& \text { script }=\text { sci_abstract\&tlng }=\text { pt }}$

MINISTERIO DE EDUCACIÓN NACIONAL -MEN. Cartilla Grado Primero Escuela Nueva. $2010 . \quad$ Disponível em: http://redes.colombiaaprende.edu.co/ntg/men/archivos/Referentes_Calidad/Modelos_Flexible s/Escuela_Nueva/Guias_para_estudiantes/MT_Grado01_01.pdf

MENDES, J. Ler, escrever e contar: práticas de numeramento-letramento dos Kaiabi no contexto de formação de professores índios no Parque Indígena do Xingu. Tese de Doutorado. Universidade Estadual de Campinas, 2001

PROFESSORES DO PARQUE INDÍGENA DO XINGU. Livro das águas. Instituto Socioambiental e Ministério de Educação. São Paulo, 2002.

PROFESSORES DO PARQUE INDÍGENA DO XINGU. Geografia indígena: Parque Indígena do Xingu/Instituto socioambiental. Brasilia: MEC/SEF/DPEF. 1988. 
PROFESSORES DO PARQUE INDÍGENA DO XINGU. Livro de alfabetização matemática em lingua indigena Panará. Material não publicado. 1999.

PROFESSORES DO PARQUE INDÍGENA DO XINGU. Livro de alfabetização matemática em lingua indigena Kawaiwete. Material não publicado. 1999.

VILELA, D.; MENDES, J. A linguagem como eixo da pesquisa em educação matemática: contribuições da filosofia e dos estudos do discurso p. 07-25. Revista Zetetike, v. 19, n. 2, p. 7-25, 2012. ISSN 2176-1744. Disponível em: <https://periodicos.sbu.unicamp.br/ojs/index.php/zetetike/article/view/8646623/13525>.

TAMAYO-OSORIO, C. Vení, Vamos hamacar el mundo, hasta que te asustes: uma terapia do desejo de escolarização moderna. 2017. Tese (Doutorado em Educação) - Universidade Estadual de Campinas. Disponível em $<$ http://repositorio.unicamp.br/jspui/handle/REPOSIP/325354 >

WITTGENSTEIN, L. Investigações Filosóficas. Tradução José Carlos Bruni. São Paulo: Nova Cultural, 1999.

\section{SOBRE AS AUTORAS}

CAROLINA TAMAYO. Doutora em Educação pela Universidade Estadual de Campinas. Coordenadora para Sul América da Red Larinoamerticana de Etnomatemática. Integrante dos grupos de pesquisa Educação, Linguagem e Práticas Culturais -PHALA - da Universidade Estadual de Campinas e Matemáticas, Educación y Sociedad-MEN- da Universidad de Antioquia (Colômbia).

JACKELINE RODRIGUES MENDES. Doutora em Linguística Aplicada pela Universidade Estadual de Campinas -UNICAMP. Professora do Departamento Ensino e Práticas Culturais da Faculdade de Educação, UNICAMP. Integrante do grupo de pesquisa Educação, Linguagem e Práticas Culturais -PHALA - da FE-UNICAMP. 